\title{
Role of CT Imaging in Oral Cavity and Oropharyngeal Squamous Cell Carcinoma
}

\author{
Khushali Shah ${ }^{1}$, Hiral Hapani ${ }^{2}$, Anjana V. Trivedi ${ }^{3}$, Chetna K. Dodiya ${ }^{4}$ \\ ${ }^{1}$ Resident Doctor, Department of Radiodiagnosis, PDUMC \& Hospital, Rajkot Gujarat, ${ }^{2}$ Assistant Professor, Department of \\ Radiodiagnosis, PDUMC \& Hospital, Rajkot Gujarat, ${ }^{3}$ Professor and Head of the Department, Department of Radiodiagnosis, \\ PDUMC \& Hospital, Rajkot Gujarat, ${ }^{4}$ Tutor, Department of Radiodiagnosis, PDUMC \& Hospital, Rajkot Gujarat, India
}

Corresponding author: Dr. Khushali Shah, 2, 'Keivalya', Opposite Yash Complex, Behind Jagruti Apartments, Gotri Road, Vadodara, Pin- 390021, Gujarat, India.

DOI: http://dx.doi.org/10.21276/ijcmsr.2020.5.1.23

BY-NC-ND

How to cite this article: Khushali Shah, Hiral Hapani, Anjana V. Trivedi, Chetna K. Dodiya. Role of CT imaging in oral cavity and oropharyngeal squamous cell carcinoma. International Journal of Contemporary Medicine Surgery and Radiology. 2020;5(1):A99-A101.

\section{A B S T R A C T}

Introduction: Squamous cell carcinoma (SCC) is one of the most common malignancies of the oral cavity and oropharynx. It is important to have a knowledge about anatomy of these two regions as the prognosis and behaviour of SCC depends on the regions of origin with those originating in oropharynx showing an aggressive pattern as compared to the ones originating in oral cavity. Study aimed to identify imaging features of SCC of the oral cavity and oropharynx on CT Scan and describe its TNM classification as well as implication of same in treatment planning.

Material and methods: In this study, 50 patients of age between 20-60 years with oral cavity lesions who were referred for further investigation to the department of radiodiagnosis, PDU Medical College and Civil hospital, Rajkot, Gujarat, over a period of 1 year from 01/10/2018 to 01/10/2019 are included. All scans were carried out on GE 16 SLICE CT scan machine. Result: The most common presentation in a patient of oral cancer was non-healing mouth sore/ ulcer and the most common site of occurrence was mandibular alveolus.

Conclusion: Our study suggests that CT scan can be used as a front line imaging modality for detection of scc of oral cavity and oropharynx and is helpful for TNM staging as well as treatment planning.

Keywords: Oral SCC, Oropharyngeal SCC, SCC, TNM Staging in Oral Cancer, CT in Oral Cancer

\section{INTRODUCTION}

Oral cancer accounts for upto $4 \%$ of all cancers in the world. Its prevalence is upto $10 \%$ of all cancers in Pakistan and upto $45 \%$ in India. ${ }^{1,2}$ More than over 300,000 new cases were diagnosed worldwide in 2004 to 2009, out of which there were 7000 deaths. $^{3}$

Squamous cell carcinoma is most common type of all oral neoplasms accounting to $90 \%$ of cases. ${ }^{4}$ Oral cancer is common in men in developing countries. There were 2, 74,300 new cases and 1, 45, 500 deaths worldwide in 2002, of which two-thirds took place in developing countries. ${ }^{5}$ Squamous cell carcinoma (SCC) is commonly evaluated with imaging modality, usually CT Scan which plays an important role in its staging. Tobacco and alcohol increases the risk of oral cancer upto fifteen times. ${ }^{6}$ Betel quid chewing also increases the risk of oral cancer. ${ }^{7-9}$ The symptoms, routes of spread and the prognosis depend on the anatomical site of origin of SCC. Therefore a radiologist must have a detailed knowledge regarding the anatomy of these two regions. The knowledge regarding anatomy and common routes of spreads is helpful for classification, staging and treatment planning. Incomplete knowledge regarding same may lead to inadequate assessment of the extent of the cancer as well as improper staging of the same which may then lead to either unnecessary on incomplete surgical resection or improper radiation therapy which may have a negative result.

This article intends to review CT findings of oral and oropharyngeal SCC with an emphasis on imaging features that affect staging and treatment planning.

Study aimed to identify radiological imaging- CT scan findings of SCC of the oral cavity and oropharynx and to evaluate the common sites of its occurrence and to describe the TNM classification and its importance in treatment planning.

\section{MATERIAL AND METHODS}

In this Single centre study, 50 patients of age between 20-60 years with oral cavity lesions who were referred for further investigation to the department of radiodiagnosis, PDU Medical College and Civil hospital, Rajkot, Gujarat, over a period of 1 year from 01/10/2018 to 01/10/2019 were included. All scans were carried out on GE 16 SLICE CT scan machine. All patients underwent plain and contrast enhanced CT scan of head and neck region extending from skull base to thoracic inlet. CT studies were reangled to avoid dental amalgam when necessary. In patients without dental 
amalgam the plane of gantry was angled parallel to hard palate. All studies were reconstructed with soft tissue and bone algorithm. None of the patients of our study had any history of previous facial/ mandibular surgery. Presence of an abnormal soft tissue mass with concominant absence of the mandibular cortex was regarded as mandibular erosion by the mass. Out of 50 patients, 45 had undergone treatment in the form of surgical resection/ mandibulectomy at our centre and the specimens were sent to the pathologist, out of which 43 were SCC .

\section{Inclusion criteria}

- All cases of oral and oropharyngeal carcinoma.

- All age and both sexes.

\section{Exclusion criteria:}

- Patients giving negative consent.

- Patients having commenced treatment.

- Patients having any contraindication for CT Scan /for radiation exposure.

\section{Machine Used: GE 16 SLICE CT SCANNER}

\section{RESULTS}

The most common presentation was non-healing mouth sore/ ulcer to be followed by lump and difficulty in swallowing. The most common site of occurrence was mandibular alveolus (45.76\%), to be followed by buccal mucosa(23.73\%);

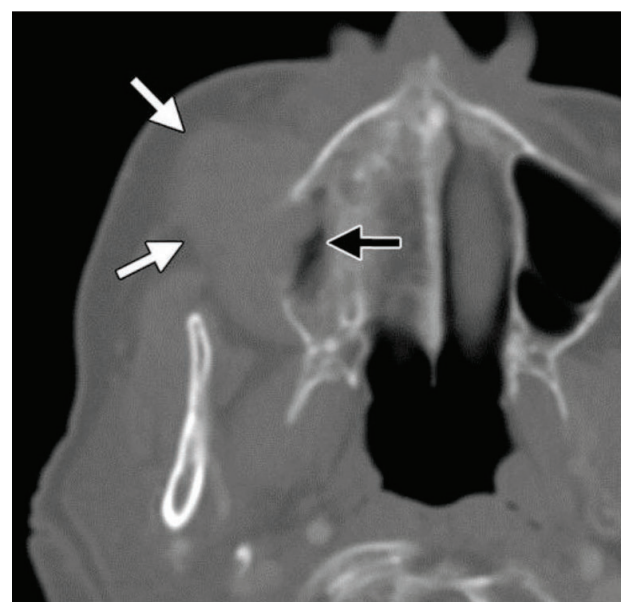

Figure-1: SCC of buccal cavity

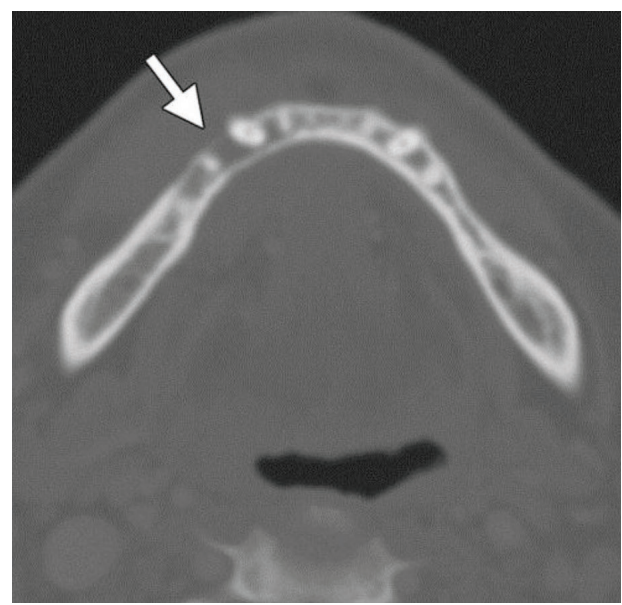

Figure-2: SCC of mandibular alveolus tongue (18.31\%), maxillary alveolus(5.76\%), lips(3\%),floor of mouth $(2 \%)$ and palate $(1.36 \%)$.

\section{Images}

Axial CECT image (bone window) which shows a buccal lesion (white arrows) which has eroded and infiltrated the right maxillary sinus (black arrow), Suggestive of a T4a lesion (fig-1).

Axial contrast-enhanced CT image (bone window) shows cortical erosion (arrow) along the right buccal aspect of the mandibular alveolus. This finding led to classification of the tumor as a T4a lesion (fig-2).

\section{DISCUSSION}

\section{TNM Staging}

Total seven stages are included- 0, I, II, III, IVA, IVB, and IVC.

Stage I or II lesions are treated with a single modalitysurgical resection or radiation therapy. Stage III or IV lesions usually require a multimodality approach including surgery, radiotherapy and chemotherapy. The site of origin of tumour plays an important role in selecting the therapeutic modalities. $^{10}$

Stage IV lesions are divided into three sub categories- IVA, IVB, IVC, based on different therapeutic strategies needed for each of them (the above mentioned revisions were introduced in 2002 in the sixth edition of the classification system). In 2007 the seventh edition, the definition of T4 lesion and stage IV disease was changed. Stage IVA and IVB suggest local-regional disease and stage IVC suggests distant metastasis. Stage IVA is for moderately advanced and stage IVB is for very advanced local-regional disease. Before 2007, T4a was resectable and T4b was for unresectable lesion. After changes made in 2007, in seventh edition, T4a is now moderately advanced and $\mathrm{T} 4 \mathrm{~b}$ is now referred as very advanced.

For stage IVA/IVB lesions, chemotherapy with radiotherapy for local-regional control is the preferred modality of treatment. For stage IVC palliative therapy is preferred.

The outcome of our study is similar to that of Close et al. ${ }^{11}$ Our study contradicts the results of recent studies which had raised a question on the ability of CT to assess the mandibular involvement in SCC. ${ }^{11-14}$

For CT assessment $3 \mathrm{~mm}$ thick slice sections were used and were reconstructed with bone and soft tissue algorithms. Brown et al. ${ }^{11}$ and Curran et al. ${ }^{12}$ used $4-5 \mathrm{~mm}$ thick slice sections without frequently using bone algorithms. Shaha ${ }^{13}$ and Bahadur ${ }^{14}$ have not described their technique and have not specified the criterias used for assessment on CT.

\section{CONCLUSION}

We evaluated 50 patients of oral cancer mainly the squamous cell type, using CECT imaging. Our study suggests that CECT can be used as a front line imaging modality for detection of oral and oropharyngeal cancers. As a result of the study we came to the conclusion that the most common site of occurrence of oral cancers is alveolus of mandible bone followed by the buccal mucosa and the least common site as per the study is palate. In the study we found that the patients of oral cancer mostly present with the complaint 
of non-healing mouth sore or ulcer followed by lump and difficulty in swallowing.

\section{Abbreviation}

1. SCC-squamous cell carcinoma

2. CECT-contrast enhanced computed tomography

3. CT- computed tomography

4. OSCC- oral squamous cell cancer

\section{REFERENCE}

1. Williams HK. Molecular pathogenesis of oral squamous carcinoma. Mol Pathol. 2000;53(2):165-72.

2. Siddiqui IA, Farooq MU, Siddiqui RA, Rafi SMT. Role of toluidine blue in early detection of oral cancer. Pak J Med Sci. 2006;22(6):184-7.

3. Sharma P, Saxena S, Aggarwal P. Trends in the epidemiology of oral squamous cell carcinoma in Western UP: an institutional study. Ind J Dent Res. 2010;21(1):316-9.

4. Choi S, Myers JN. Molecular pathogenesis of oral squamous cell carcinoma: implications for therapy. J Dent Res. 2008;87(4):14-32.

5. Ferlay J, Parkin DM, Pisani P. GLOBOCAN 2002: cancer incidence, mortality and prevalence worldwide. Lyon: IARC Press; 2004.

6. Ogden GR. Alcohol and oral cancer. Alcohol. 2005;35(5):169-73.

7. Su CC, Yang HF, Huang SJ, LianIe B. Distinctive features of oral cancerin Changhua County: high incidence, buccal mucosa preponderance, and a close relation to betel quid chewing habit. J Formos Med Assoc. 2007;106(1):225-33.

8. Ko YC, Huang YL, Lee CH, Chen MJ, Lin LM, Tsai CC. Betel quid chewing, cigarette smoking and alcohol consumption related to oral cancer in Taiwan. J Oral Pathol Med. 1995;24(10):450-3.

9. Subapriya R, Thangavelu A, Mathavan B, Ramachandran CR, Nagini S. Assessment of risk factors for oral squamous cell carcinoma in Chidambaram,Southern India: a case-control study. Eur J Cancer Prev. 2007;16(1):251-6.

10. National Comprehensive Cancer Network, Forastiere AA, Ang KK, et al. Head and neck cancers. J NatlComprCancNetw 2008;6(7):646-695. 4. Mukherji SK, Castelijns J, Castillo M. Squamous

11. Bruening RD, Sturm C, Jaeger LJ, Schoepf UO, Becker MD, Reiser MF. Subsecond multiple detector CT improves imaging of the larynx. (abstr) Radiology 1999; 213(4):278-279

12. Curran AJ, Toner M, Quinn A, Wilson G, Timon C. Mandibular invasion diagnosed by SPECT. Clin Otolaryngol 1996; 21(1):542-545

13. Shaha AR. Preoperative evaluation of the mandible in patients with carcinoma of the floor of the mouth. Head Neck 1991; 13(5):398-402

14. Bahadur S. Mandibular involvement in oral cancer. J Laryngol Otol 1990; 104(3):968-971

Source of Support: Nil; Conflict of Interest: None

Submitted: 03-12-2019; Accepted: 21-01-2020; Published online: 20-02-2020 